\title{
Through Station Capacity Calculation Models for Through Operation between Urban Rail Transit and Suburban Railway
}

\author{
Minggao $\mathrm{Li}^{1} \mathrm{a}^{*}$, Peng Du ${ }^{1, \mathrm{~b}}$, Ruijia SHI ${ }^{1, \mathrm{c}}$, Wei Zeng ${ }^{1, \mathrm{~d}}$ and Ying $\mathrm{Li}^{1, \mathrm{e}}$ \\ ${ }^{1}$ MOE Key Laboratory for Urban Transportation Complex Systems Theory and Technology, Beijing \\ Jiaotong University, Beijing 100044 P. R. China \\ aliminggao1989@126.com, bpdu@bjtu.edu.cn, ${ }^{c} 13114224 @ b j t u . e d u . c n,{ }^{d} 14114240 @ b j t u . e d u . c n$, \\ e15125765@bjtu.edu.cn
}

Keywords: Urban Rail Transit; Suburban Railway; Through Operation; Through Station Capacity Abstract. With the development of metropolitan, through operation between urban rail transit and suburban railway is the development trend in the future. In this study, the general concepts in the TCRP Transit Capacity and Quality of Service Manual were adopted, followed by the development of a set of comprehensive through station capacity models with consideration of a complete set of possible movements at through station. These models were implemented and validated by a through station in Tokyo rail transit system. The case study shows that the results calculated from the proposed model are very close to the actual values. The proposed capacity models can help rail transit operators with similar operational environments to monitor their systems' performance and identify critical bottlenecks.

\section{Introduction}

Rail transit systems are often the backbone of the transportation system in major cities. The residents' travel distance increases gradually with the development of metropolitan, and the limited coverage of traditional urban rail transit is difficult to meet the travel demand of residents in metropolitan area. Through operation between urban rail transit and suburban railway, which can realize resources sharing, expand the service of rail transit, reduce transfer time, is the developing trend in metropolitans.

Through operation is a kind of operation that the train moves in different lines, which belong to different companies. Thus different rail systems share a distance of the same tracks in through operation[1]. Under through operation, the station connecting different lines is through station. Through operation is popularly applied in Japan, 10 of 13 Tokyo metros and theirs connection suburban railways are through operation. The through operation between tram and railway are well developed in Europe, such as German and England [2,3]. With the development of integration in Beijing-Tianjin-Hebei regions, through operation among railway systems is taken into consideration. Moreover, $1000 \mathrm{~km}$ suburban railways are to be built in Beijing to connect Beijing suburban regions. Therefore, through operation between urban rail transit and suburban railway is the inevitable trend in Beijing in the future.

The assessment of rail capacity plays an important role in monitoring the performance of an existing system. In a transit system, the critical track layouts are those locations that may become capacity bottlenecks, while intermediate stations, turn-back locations, and junctions are usually the critical locations[4]. Through station can be both intermediate station and turn-back location, its capacity is the capacity bottlenecks. So the through station capacity is critical to the performance of through operation.

The train type heterogeneity has impact on the capacity[5,6]. For through operation, different kinds of trains pass through station. Therefore, the existing station capacity calculation methods, which are for single rail system, are not suitable for through station connecting multi-types rail transit.

To calculate the through station capacity, this research adopted some of the general concepts in TCQSM and literature[7], and then developed a generic and comprehensive through station capacity calculation model. Rail transit capacity is highly dependent on the type of signaling system and critical track layouts[4]. In this paper, we just study the capacity in different through station layouts with moving-block signaling system. 
The remainder of this article is structured as follows. Section 2 presents the mathematical model for the through station capacity. Empirical studies are summarized in Section 3 and the final section offers conclusions.

\section{Mathematical Model of Through Station Capacity}

\section{Notations and Definitions}

Stopping shadow of a vehicle: the distance in front of the vehicle equal to its stopping distance for a given braking rate. As this distance "travels" with vehicle, it creates a "shadow area", shown in Figure 1b.

Shadow area increases with speed, assuming that all other factors are constant.

Stopping shadow line: the line (i.e., set of points) that the stopping distance "draws" as the vehicle travels. It represents the front of the shadow area. When a vehicle travels at constant speed, its shadow line and the position of its front end are parallel. When it approaches a station and decelerates, its shadow line extends to the far end of the station platform and then becomes a horizontal line. The path of the vehicle's front end during braking converges with the shadow line and coincides with it when vehicle is stopped, as Figure $1 \mathrm{~b}$ shows.

Passing train: the train that moving on the same line when finished boarding and alighting.

Through train: the train that moving to another line when finished boarding and alighting.

$a_{i}$ : acceleration rate of train $i, \mathrm{~m} / \mathrm{s}^{2} . i=1,2,3.1$ is through train, 2 is passing train, 3 is turnback train.

$b_{i}$ : deceleration rate of train $i, \mathrm{~m} / \mathrm{s}^{2}$.

$l_{c}$ : length of crossover, $\mathrm{m}$.

$l_{s}$ : length of station, and is equal to train length, $\mathrm{m}$.

$l_{s-c}:$ distance from the crossover to the station, $\mathrm{m}$.

$v^{*}:$ turnout speed, $\mathrm{m} / \mathrm{s}$.

$v_{i}$ : maximum operation speed of train $i, \mathrm{~m} / \mathrm{s}$.

$t_{s}:$ dwell time, $s$.

$t_{e}$ : switch throw and lock time, s.

$t_{r}$ : reaction time for driver and control system, $\mathrm{s}$.

$f$ : braking safety factor, less-than-full braking efficiency is fof normal braking, $f<1$.

\section{Calculation Models}

Based on the practical through stations layouts between subway and suburban railway in Tokyo, Y-typed through station is one of the most complicated, which services through train, passing train and turn-back trains. Furthermore, it is wide application in practice. Therefore, the Y-typed through station was chosen to demonstrate the derivation. The layout of the Y-typed through station is shown as Figure 1a. The black line in Figure 1a is subway line(or suburban rail line), and the blue line is suburban rail line(or subway line).

In Figure 1a, the red train(passing train) moves on black line all the time, the blue train(turn-back train) moves on blue line and turn back at the through station, the black train(through train) moves on blue line before getting the through station, then moves on black line when finished boarding and alighting at the through station.

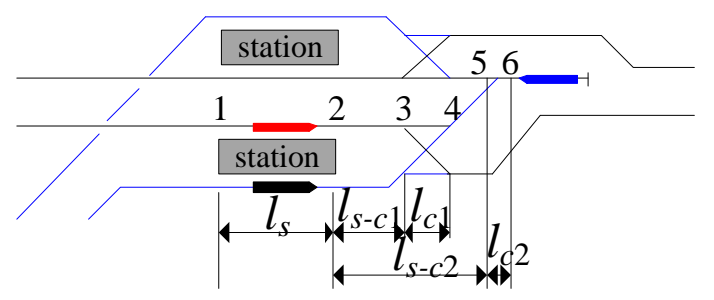

Fig. 1a Layouts 


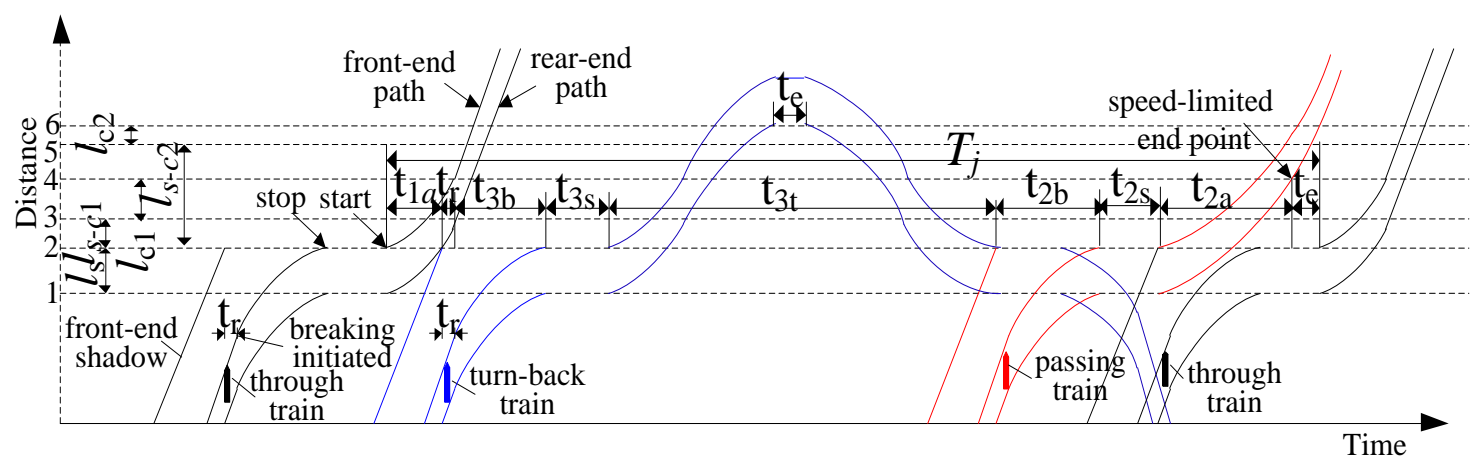

Fig.1b Time-distance of through train, turn-back train and passing train.

Fig. 1 Y-typed through station

The through station capacity is defined here as a measure of the ability to move a specific amount of train over a defined direction under a specific service plan (or level of service) in a given period of time, typically an hour. We assume that the trains are dispatched by periodical in urban rail system. So the overall framework of capacity analysis for a given through station is to calculate the cycle time and the amount of train in a cycle time. The first phase of the framework is to analysis the process of train arriving and departure. Then, the amount of train in a cycle time can be calculated. In the second phase, each part of the time is calculated according to kinematic formula, and the cycle time is calculated.

Figure $1 \mathrm{~b}$ is the time-distance of the three trains(black lines for through train, blue lines for turn-back train and red lines for passing train) in Y-typed through station. For a Y-typed through station, through train arrives to through station and stops for boarding and alighting, then moves to the other line. When the through train rear-end leaves platform (position 2 in Figure 1a), the turn-back train arrives and stops for boarding and alighting, then turns back. When the turn-back train rear-end arrives platform (position 2 in Figure 1a), the passing train gets in. When the passing train rear-end leaves crossover (position 4 in Figure 1a), the next through train can departure after $t_{e}$. The trains arrive and departure in cycle.

Figure $1 \mathrm{~b}$ and Equation 1 identify the components of periodic time for a Y-typed through station:

$$
T_{j}=t_{1 a}+t_{3 b}+t_{3 s}+t_{3 t}+t_{2 b}+t_{2 s}+t_{2 b}+t_{e}+2 t_{r}
$$

$t_{1 a}$ is the time for through train to clear the platform, $t_{3 b}$ is the braking time for turn-back train, $t_{3 t}$ is the turn back time. $t_{2 b}$ is the braking time for passing train, $t_{2 s}, t_{3 s}$ are the dwell time of passing train and turn-back train, respectively. Dwell time is affected by the numbers of passengers boarding and alighting, the train doors, the time for door opening and closing. $t_{r}$ is reaction time for driver and control system, and $t_{e}$ is the conversion time while turn back. They can be formulated as follow:

$$
\begin{aligned}
& t_{1 a}=\sqrt{\frac{2 l_{s}}{a_{1}}} \\
& t_{3 b}=\frac{v_{3}}{f b_{3}} \\
& t_{3 t}=2 \sqrt{\frac{l_{s}+l_{s-c 1}+l_{c 1}}{a_{3}}}+t_{e} \\
& t_{2 b}=\frac{v_{2}}{f b_{2}} \\
& t_{2 a}=\frac{l_{s}+l_{s-c 1}+l_{c 1}}{v^{*}}
\end{aligned}
$$


The capacity of Y-typed through station $(N)$ is:

$$
N=3 \times \frac{3600}{T_{j}}
$$

Equation 7 is the capacity of Y-typed through station when through train, turn-back train and passing train are alternately dispatched by $1: 1: 1$. When they are alternately dispatched by $m: n: l$, the equations can be rewritten as follow:

$$
N=\frac{3600(m+n+l)}{t_{1 a}+(m-1)\left(t_{1 a}+t_{r}+t_{1 b}+t_{1 s}\right)+n\left(t_{r}+t_{3 b}+t_{3 t}+t_{3 s}\right)+l\left(t_{r}+t_{2 b}+t_{2 s}\right)+(l-1) t_{2 a(1,2)}+t_{2 a}}
$$

With Equations 2 6, Equations 8, the Y-typed through station capacity can be rewritten as follow.

$$
N=\frac{3600(m+n+l)}{\left\{\begin{array}{l}
\sqrt{\frac{2 l_{s}}{a_{1}}}+(m-1)\left(\sqrt{\frac{2 l_{s}}{a_{1}}}+\frac{v_{1}}{f b_{1}}+\mathrm{t}_{1 s}\right)+n\left(\frac{v_{3}}{f b_{3}}+t_{3 s}+2 \sqrt{\frac{l_{s}+l_{s-c 1}+l_{c 1}}{a_{3}}}+t_{e}\right)+l\left(\frac{v_{2}}{f b_{2}}+t_{2 s}\right) \\
+(l-1) \sqrt{\frac{2 l_{s}}{a_{2}}}+\frac{2\left(l_{s}+l_{c 2}+l_{s-c 2}\right)}{v^{*}}+(m+n+l-1) t_{r}
\end{array}\right\}}
$$

\section{Case Study}

Through operation between subway and suburban railway is widely used in Tokyo. 10 of 13 subway lines are adopted through operation with suburban railway, as Figure 2 shows. In this case study, Sengakuji Station, one of the through stations in Tokyo railway system was chosen to demonstrate and validate the proposed capacity models.

Sengakuji Station is the through station of Asakusa Line (subway) and Keikyu Main Line (suburban railway). The average daily passengers of Sengakuji Station are 352,803 in 2013. Figure 3 is the layouts of Sengakuji Station. There are through trains, passing trains and turn-back trains passing through Sengakuji Station. The workday timetables of Sengakuji Station in 8:00-9:00 and 12:00-13:00 are shown as Table 1 [8]. 


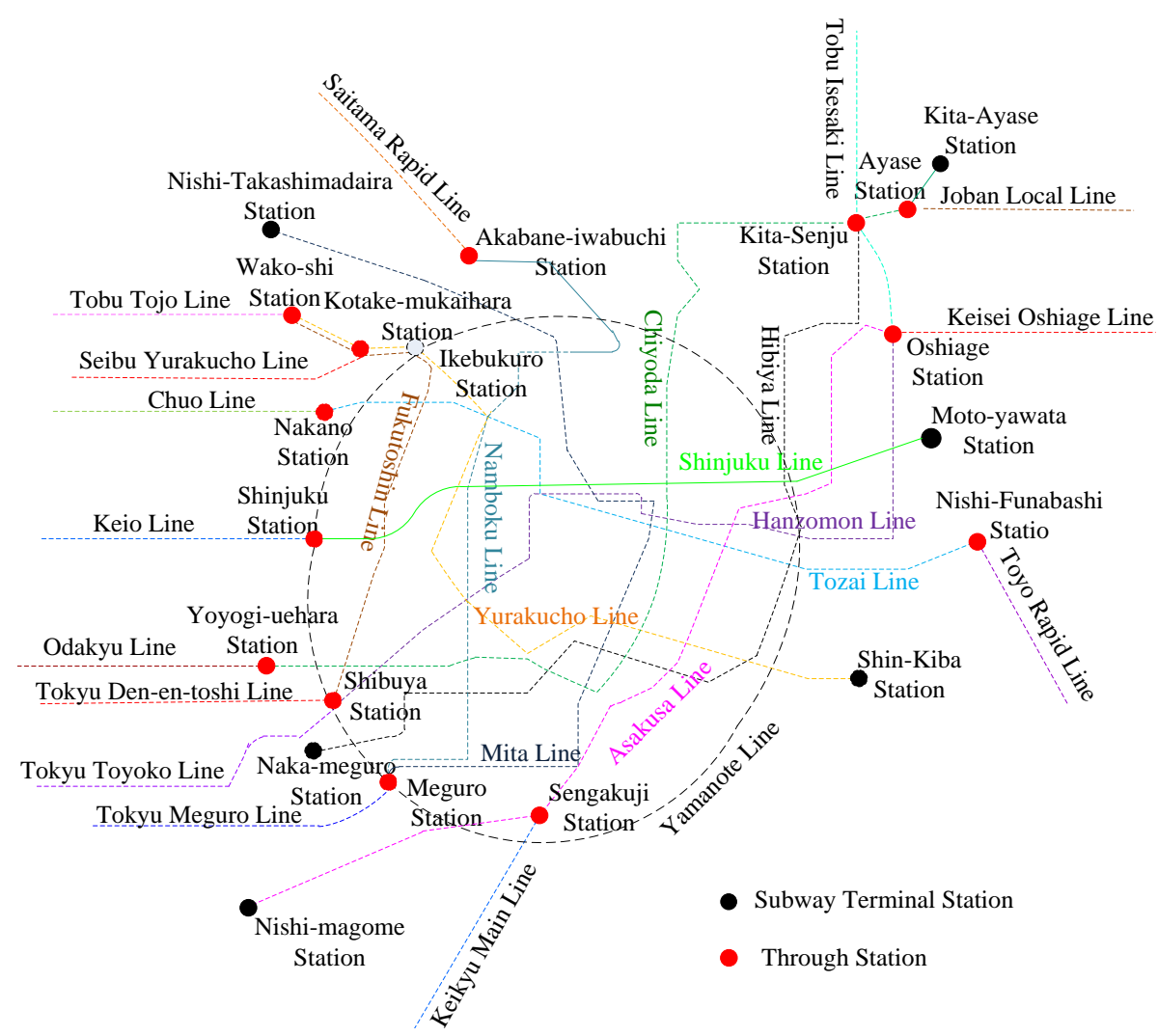

Fig.2 Through operation between subway and suburban railway in Tokyo.

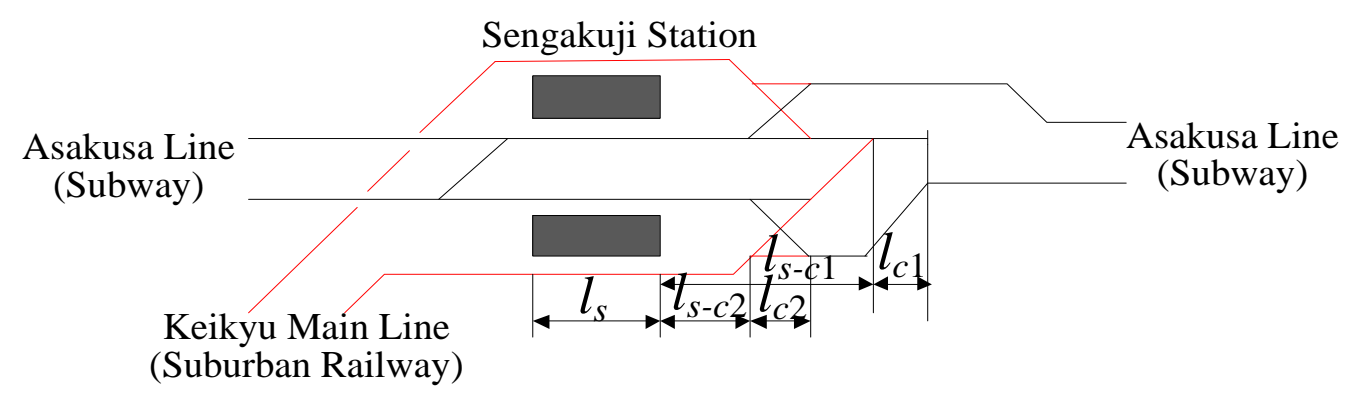

Fig. 3 Layouts of sengakuji station.

Table 1 Workday timetable of sengakuji station

\begin{tabular}{|c|c|c|c|c|}
\hline From & To & Via & Time & \\
\hline $\begin{array}{l}\text { Shinagawa Station } \\
\text { (Keikyu Main Line) }\end{array}$ & $\begin{array}{l}\text { Oshiage Station } \\
\text { (Asakusa Line) }\end{array}$ & \multirow{4}{*}{$\begin{array}{l}\text { Sengakuji } \\
\text { Station }\end{array}$} & \multirow{2}{*}{ 8:00-9:00 } & $\begin{array}{l}8: 00,8: 05,8: 08,8: 14, \\
8: 19,8: 25,8: 32,8: 38, \\
8: 43,8: 49,8: 54\end{array}$ \\
\hline $\begin{array}{l}\text { Nishi-magome Station } \\
\text { (Asakusa Line) }\end{array}$ & $\begin{array}{l}\text { Oshiage Station } \\
\text { (Asakusa Line) }\end{array}$ & & & $\begin{array}{l}8: 03,8: 10,8: 16,8: 22, \\
8: 27,8: 30,8: 35,8: 40, \\
8: 46,8: 51,8: 57\end{array}$ \\
\hline $\begin{array}{l}\text { Shinagawa Station } \\
\text { (Keikyu Main Line) }\end{array}$ & $\begin{array}{l}\text { Sengakuji Station } \\
\text { (Keikyu Main Line) }\end{array}$ & & \multirow{3}{*}{ 12:00-13:00 } & $12: 04,12: 24,12: 44$ \\
\hline $\begin{array}{l}\text { Shinagawa Station } \\
\text { (Keikyu Main Line) }\end{array}$ & $\begin{array}{l}\text { Oshiage Station } \\
\text { (Asakusa Line) }\end{array}$ & & & $\begin{array}{l}12: 01,12: 10,12: 15 \\
12: 21,12: 30,12: 35 \\
12: 41,12: 50,12: 55\end{array}$ \\
\hline $\begin{array}{l}\text { Nishi-Magome Station } \\
\text { (Asakusa Line) }\end{array}$ & $\begin{array}{l}\text { Oshiage Station } \\
\text { (Asakusa Line) }\end{array}$ & & & $12: 05,12: 25,12: 45$ \\
\hline
\end{tabular}


Table 2 is the parameters values and Table 3 shows the computational results for the Sengakuji Station. The calculated capacity is 25 trains/h when through train and passing train were alternately dispatched by 1:1. The actual trains passing through Sengakuji Station in morning peak 8:00-9:00 are 22 (11 through trains and 11 passing trains), which are very close to the results calculated from the proposed model.

The calculated capacity is 23 trains/h when through train, turn-back train and passing train were alternately dispatched by 3:1:1. The actual trains passing through Sengakuji Station in 12:00-13:00 are 15 (9 through trains, 3 turn-back trains and 3 passing trains). Passengers decline in 12:00-13:00, and the dispatched trains decrease correspondingly. So the actual dispatched trains are less than the calculated capacity.

Table 2 Parameters values

\begin{tabular}{cccccc}
\hline Variables & Values & Variables & Values & Variables & Values \\
\hline$l_{s}$ & $200 \mathrm{~m}$ & $v_{3}$ & $120 \mathrm{~km} / \mathrm{h}$ & $a_{3}$ & $0.83 \mathrm{~m} / \mathrm{s}^{2}$ \\
$l_{s-c 1}$ & $5 \mathrm{~m}$ & $v^{*}$ & $35 \mathrm{~km} / \mathrm{h}$ & $b_{1}$ & $1 \mathrm{~m} / \mathrm{s}^{2}$ \\
$l_{c 1}$ & $45 \mathrm{~m}$ & $t_{r}$ & $2 \mathrm{~s}$ & $b_{2}$ & $1 \mathrm{~m} / \mathrm{s}^{2}$ \\
$l_{c 2}$ & $300 \mathrm{~m}$ & $t_{s}$ & $60 \mathrm{~s}$ & $b_{3}$ & $1 \mathrm{~m} / \mathrm{s}^{2}$ \\
$l_{s-c 2}$ & $200 \mathrm{~m}$ & $t_{e}$ & $15 \mathrm{~s}$ & $t_{r}$ & $2 \mathrm{~s}$ \\
$v_{1}$ & $120 \mathrm{~km} / \mathrm{h}$ & $a_{1}$ & $0.83 \mathrm{~m} / \mathrm{s}^{2}$ & $t_{e}$ & $15 \mathrm{~s}$ \\
$v_{2}$ & $70 \mathrm{~km} / \mathrm{h}$ & $a_{2}$ & $0.83 \mathrm{~m} / \mathrm{s}^{2}$ & - & - \\
\hline
\end{tabular}

Table 3 Capacity computation results of sengakuji station

\begin{tabular}{ccccc}
\hline Period & Ways & $m: n: l$ & $T_{j}(\mathrm{~s})$ & $N($ train/h) \\
\hline \multirow{2}{*}{$8: 00-9: 00$} & Calculation & $1: 0: 1$ & 281 & 25 \\
& Practical & $11: 0: 11$ & - & 22 \\
\multirow{2}{*}{ 12:00-13:00 } & Calculation & $3: 1: 1$ & 755 & 23 \\
& Practical & $9: 3: 3$ & - & 15 \\
\hline
\end{tabular}

\section{Conclusions}

The capacity of through station is important to the performance of through operation. A set of comprehensive capacity models was developed based on the analysis of train travelling process in through station. These models were implemented and validated by the case study of Sengakuji Station, one of the through stations in Tokyo rail transit system. The result shows that Sengakuji Station capacity is 25 trains/h when the through train and passing train were alternately dispatched by $1: 1$, and is 23 trains/h when through train, turn-back train and passing train were alternately dispatched by 3:1:1. The proposed capacity models can help operators easily monitor their systems' performance and identify critical bottlenecks in the systems.

\section{Acknowledgements}

The authors are grateful to the National Basic Research Program (2012CB725406), the National Natural Science Foundation (71131001) for their financial supports on this work. We are grateful to anonymous referees for their valuable comments and suggestions.

\section{References}

[1] B. H. Mao, M. J. Liu, R. Huang, and P. Du. Operational Theories and Key Technologies of Rail Transit Networks. Science Press, Beijing(2011). in Chinese. 
[2] T. Griffin. Shared Track-A New Dawn?. Proceedings of the Institution of Mechanical Engineers, Part F: Journal of Rail and Rapid Transit, Vol. 216, No.1, pp. 15-22(2002).

[3] M. Novales, A. Orro, and M. R. Bugarin. The Tram-Train: State of the Art. Proceedings of the Institution of Mechanical Engineers, Part F: Journal of Rail and Rapid Transit, Vol. 216, No. 1, pp. 1-13(2002).

[4] Kittelson\&Assoc, Inc., Parsons Brinckerhoff, Inc., KFH Group, Inc., Texam A\&M Transportation Institute, \& Arup. TCRP Report 165: Transit Capacity and Quality of Service Manual, Third Edition. Transportation Research Board of the National Academies, Washington, D. C.(2013).

[5] M. H. Dingler, Y. C. Lai, and C. P. L. Barkan. Impact of Train Type Heterogeneity on Single-Track Railway Capacity. Transportation Research Record: Journal of the Transportation Research Board, No. 2117, Transportation Research Board of the National Academies, Washington, D.C., pp. 41-49(2009).

[6] J. Z. Zheng, and J. Liu. Carrying Capacity of Beijing-Shanghai High-Speed Railway by Different Transport Organization Patterns. Journal of Transportation Systems Engineering and Information Technology, Vol. 12, No.4, pp. 22-28(2012).in Chinese.

[7] V. R. Vuchic. Urban Transit Systems and Technology. John Wiley \& Sons, Inc., New York(2007).

[8] Information on http:/transit.yahoo.co.jp/station/time/22775/?gid=3381\&kind=1\&done=time . 